\title{
Uma espécie de coração
}

\author{
A kind of heart
}

Paloma Roriz

\section{Resumo:}

Por meio da contextualização de uma frase de Nietzsche, empregada de diferentes modos pelo escritor português Manuel António Pina, e de seu possível desdobramento na construção da relação entre a figura do convalescente e a da criança enquanto índice emblemático de modernidade poética, o presente artigo propõe uma reflexão acerca da controvertida entonação lírica presente em alguns dos poemas de Pina. Para isso, são apontadas algumas direções problematizantes em torno da associação entre experiência emocional e experiência poética, com base no estatuto discursivo do sujeito lírico no contexto de surgimento e consolidação da poesia moderna, levando em conta seus reflexos posteriores na produção portuguesa mais recente.

Palavras-chave: Modernidade. Lirismo. Poesia portuguesa contemporânea. Manuel António Pina.

\begin{abstract}
:
Based on the contextualization of a phrase by Nietzsche, used in different ways by the Portuguese writer Manuel António Pina, and its possible development in the construction of the relationship between the figure of the convalescent and that of the child, as an emblematic index of poetic modernity, this article proposes a reflection on the lyric intonation present in
\end{abstract}

Doutora em Literatura Comparada pela Universidade Federal Fluminense. Integrante dos Grupos de Pesquisa Poesia e contemporaneidade e Estudos de Paisagem nas Literaturas de Língua Portuguesa [UFF/CNPq]. Professora colaboradora no Curso de Especialização em Literatura Infantojuvenil do Programa de Pós-Graduação Lato Sensu em Letras da UFF. 
a controversial way in some of Pina's poems. For this, some issues and directions are pointed out around the association between emotional experience and poetic experience, based on the discursive status of the lyrical subject, in the context of the emergence and consolidation of modern poetry, taking into account their later reflections in the most recent Portuguese production.

Keywords: Modernity. Lyricism. Contemporary Portuguese poetry. Manuel António Pina.

\section{Uma segunda, mais perigosa inocência}

Em seu pequeno livro intitulado Que emoção! Que emoção?, Georges Didi-Huberman explica o título de sua conferência ${ }^{2}$ com base na imagem do choro de uma criança numa foto, da qual depreende os detalhes da expressão comprimida pelos gritos e lágrimas, donde o ponto de exclamação que emoção!, espanto diante da imagem da criança convulsionada, e espanto associado ainda ao gesto filosófico por excelência, o de "se espantar diante de algo, de alguém, de uma experiência" (DIDIHUBERMAN, 2016, p. 10). Didi-Huberman reporta-se a fotos de crianças em prantos encomendadas por Charles Darwin para o livro A expressão das emoções no homem e nos animais (publicado pela primeira vez em 1872), no qual procurava comprovar que o ato de chorar seria um ato "primitivo", ou seja, um estado encontrado sobretudo em crianças, animais, mulheres (principalmente as loucas), idosos e doentes mentais. Contudo, para ser propriamente filosófico, o gesto demandaria ainda a formulação de uma pergunta, que emoção?: "o que se entende por emoção? Que tipo de emoção? Por que a emoção?” (DIDI-HUBERMAN, 2016, p. 11). Ao recordar que muitos filósofos antigos tomariam a emoção como noção

2 O livro é a transcrição de uma palestra proferida em 2013, em Montreuil, na França, dentro da programação intitulada Pequenas conferências organizada pela diretora de teatro Gilberte Tsaï (inspirada nas emissões realizadas por Walter Benjamin para crianças entre os anos de 1929 e 1932) e dirigida a crianças e jovens. 
negativa, como "fraqueza", "defeito", "impotência", o autor menciona, como contrapartida, primeiramente Hegel, com a dignidade recobrada do páthos perante o logos, e, a seguir, Nietzsche, em sua tomada privilegiada dos poetas trágicos em relação aos pensadores lógicos.

É com esse horizonte em mente que talvez possamos entender certo uso de uma passagem nietzschiana, encontrada no livro A gaia ciência, feito pelo escritor português Manuel António Pina, e tomada como possível eixo norteador de sua poética, como já bem sugerido no título de um de seus poemas, "Uma segunda e mais perigosa inocência"3 (PINA, 2012, p. 68), que diz:

Quem desenterrará o que é preciso esquecer?

O escritor torna-se retórico com cega serenidade, Será preciso passar para o lado de fora, flutuar?

Escrevo aquilo que não posso, transformo-me no que me proponho destruir. Já não é uma Literatura, é uma Fatalidade.

Aquele que quer morrer é aquele que quer conservar a vida, a tristeza daquele que fala ri-se de tudo, que sentido faz isto e que sentido não faz isto?

(PINA, 2012, p. 68)

A obra de Nietzsche A gaia ciência, lançada originalmente em 1882, é apontada como sintetizadora de formulações decisivas do seu pensamento, como a morte de Deus, o eterno retorno, a crítica à moral, a

3 Em entrevista dada a Luís Miguel Queirós, Manuel António Pina afirma: "A infância é algo que só se tem quando se perde, porque as crianças estão perto de mais (sic) da infância para se aperceberem dela. Como em outras poesias, na minha a infância - a palavra 'infância' e a ideia de infância mais do que a concreta memória de uma infância - é, julgo eu, a melancolia da 'primeiridão', de um tempo mítico em que olhámos o mundo e a nós próprios pela primeira vez, com olhos inocentes de palavras e de memória, isto é, 'não embaciados de nenhuma palavra/e nenhuma lembrança'. Não é a inocência da criança, que é uma inocência inocente, mas uma nietzschiana 'segunda e mais perigosa inocência', uma inocência que se sabe inocente, ou então apenas uma espécie de vontade de inocência" (QUEIRÓS, 2011, n.p.). Já em entrevista à Ciber-kiosk, como bem lembra Rui Lage, Pina declara: "Os poemas de Aquele que quer morrer radicam, fundamentalmente, em duas leituras (os livros geram outros livros): o Tao Te King e A gaia ciência, de Nietzsche" (PINA, 2016, p. 18). 
vontade de poder, a noção de corpo. O livro seria elaborado na sequência de um anterior, Aurora, publicado em 1881, escrito, por sua vez, quando o filósofo estava muito doente e desenganado pelos médicos. Assim, A gaia ciência surge no ano seguinte, quando o autor se recuperava em Gênova, sentindo a confiança da saúde reconquistada. É o seu livro com maior variedade de formas, entre versos, diálogos, parábolas, aforismos, alegorias - já a sua abertura conta com uma seção de "epigramas", intitulada “'Brincadeira, astúcia e vingança' - prelúdio em rimas alemãs", numa alusão direta a um título de libreto escrito por Goethe em 1790, musicado por Peter Gast em 1880 -, com o título tomado, como indica Paulo Cézar de Souza:

da expressão com que os trovadores provençais (séculos XI-XIV) designavam a sua arte: gai saber ou gaia scienza (no subtítulo original está gaya; a ortografia não é estabelecida, pois são formas linguísticas da Idade Média). Mas já no prólogo percebemos que Nietzsche lhe ampliou a significação. Esse título tem primeiramente um sentido pessoal, neste que ele próprio considerava o mais pessoal de seus livros: é o canto de convalescença de alguém que muito sofreu e agora sente que lhe volta o vigor. (SOUZA, 2012, p. 306, grifo do autor)

O teor de alegria é de fato notado já no prólogo do livro, quando lemos o aviso de que dele emanaria a gratidão por algo inesperado, a gratidão de um convalescente:

"Gaia ciência": ou seja, as saturnais de um espírito que pacientemente resistiu a uma longa, terrível pressão - pacientemente, severa e friamente, sem sujeitar-se, mas sem ter esperança -, e que repentinamente é acometido pela esperança, pela esperança de saúde, pela embriaguez da convalescença. (NIETZSCHE, 2012, p. 9)

É então na quarta seção do prólogo que encontramos o trecho ao 
qual Manuel António Pina se reporta, quando o filósofo adverte:

Por fim, para que o essencial não deixe de ser registrado: de tais abismos, de tal severa enfermidade, também da enfermidade da grave suspeita voltamos renascidos, de pele mudada, mais suscetíveis, mais maldosos, com gosto mais sutil para a alegria, com língua mais delicada para todas as coisas boas, com sentidos mais risonhos, com uma segunda, mais perigosa inocência na alegria, ao mesmo tempo mais infantis e cem vezes mais refinados do que jamais fôramos antes. (NIETZSCHE, 2012, p. 13)

A ideia da convalescença atesta de início o lugar que o corpo recebe, sendo inclusive ainda no prólogo que Nietzsche alude à dimensão do corpo físico no pensamento dos filósofos, que encobririam, sob o inconsciente "disfarce" da objetividade, necessidades fisiológicas: "frequentemente me perguntei se até hoje a filosofia, de modo geral, não teria sido apenas uma interpretação do corpo e uma má-compreensão do corpo" (NIETZSCHE, 2012, p. 11). Além disso, não é difícil associar diretamente a convalescença ligada a um estado de embriaguez, alegria e novidade ao célebre ensaio de Baudelaire sobre o desenhista Constantin Guys de Sainte-Hélène, publicado originalmente em 1863, "O pintor da vida moderna". É na terceira parte, intitulada "O artista, homem do mundo, homem das multidões e criança", que lemos a referência ao conto de Edgar Allan Poe, quando a figura do convalescente surge "atrás das vidraças de um café" (BAUDELAIRE, 1995, p. 856), aspirando com deleite "todos os indícios e eflúvios da vida". Logo em seguida, temos a conhecida associação entre a convalescência e a infância:

Ora, a convalescência é como uma volta à infância. $\mathrm{O}$ convalescente goza, no mais alto grau, como a criança, da faculdade de se interessar intensamente pelas coisas, mesmo por aquelas que aparentemente se mostram as mais triviais. Retornemos, se possível, através de um 
esforço retrospectivo da imaginação, às mais jovens, às mais matinais de nossas impressões, e constataremos que elas possuem um singular parentesco com as impressões tão vivamente coloridas que recebemos ulteriormente, depois de uma doença, desde que esta tenha deixado puras e intactas nossas faculdades espirituais. A criança vê tudo como novidade, está sempre inebriada. (BAUDELAIRE, 1995 , p. 856, grifo do autor)

Poderíamos inferir disso que a ideia de uma segunda inocência, como a evocada por Manuel António Pina, se aproximaria, precisamente, desse retorno propiciado pelo estado do convalescente, o que implicaria uma reinscrição da imagem da criança como índice privilegiado da modernidade poética, e, portanto, um desejo tardio de reatualização de um topos de modernidade. No entanto, mais do que isso, e já a levar em conta algo da ironia tão presente em sua poesia, a ideia de uma convalescença implícita na referência à passagem de Nietzsche parece também não deixar de aludir a um entendimento de "recuperação" num duplo e contraditório sentido: como algo restaurado, "recuperado", no apelo tardio a um certo sentido de modernidade subliminarmente presente em sua poesia, e, ao mesmo tempo, a de um estado já superado, uma enfermidade fisiológica e concretamente vencida pela consciência inapelável do presente e de um "Passado" irresgatável. Uma infância não em segundo, mas em terceiro grau, poderíamos dizer. Mesmo que a enfermidade não venha a ser de todo vencida.

\section{Entre indiferença e indiferença}

Convalescença significa, segundo o dicionário, um "período de transição depois de uma enfermidade, no qual se processa a recuperação gradativa das forças e da saúde" (HOUAISS, 2009, p. 542). Um pouco dessa transição, desse estado intermédio, nem cá, nem lá, parece ganhar 
um contorno privilegiado no livro de Pina intitulado Cuidados intensivos, de 1994. O autor, de fato, havia passado por um período de internação hospitalar, em decorrência de uma complicação mais séria de saúde. O termo "cuidados intensivos" deriva de outro, "medicina intensiva", voltado para pacientes em estado crítico e que demandam monitoramento ininterrupto, mas os "cuidados intensivos" são dirigidos a pacientes em condições potencialmente reversíveis, com chances de recuperação e de sobrevivência. É nesse sentido que o título parece se referir, de algum modo, à ideia de uma transição, uma abertura, um espaço intervalar, oscilatório e frágil, entre uma interioridade e uma exterioridade. É um livro de certo pendor dramático, embora sempre amortecido pela entoação algo distanciada, contrabalançada, contudo, por um tom próximo, por vezes quase doméstico, de fala ao pé do ouvido, em que a figura do "coração" em meio aos versos é reincidente. Um dos recursos do autor para sustentar a impessoalidade do sujeito poético parece ser, na seção intitulada "monólogos", por exemplo, o uso irônico de aspas ao início e final dos poemas, como se se tratasse da fala de um outro - na reiteração de uma desestabilização da voz enunciativa tão própria aos seus poemas -, com marcas de datação ao fim de cada um, indicando o dia da semana e do mês, o que aludiria a uma encenação descritiva e sequencial de diário ou registro biográfico. Em alguns deles, é possível mesmo entrever um movimento irregular próprio ao ritmo respiratório, no emprego de versos ora mais curtos, fracionados, com dois, três vocábulos, como se dessem a entender um fôlego entrecortado, um uso do ar restrito à articulação de palavras rápidas de aviso, de lembrete, de recomendação, ora mais alongados: 
no gravador de chamadas;

rega as roseiras;

as chaves estão

na mesa do telefone;

traz o meu

caderno de apontamentos

(o de folhas

sem linhas, as linhas distraem-me).

Não digas nada

a ninguém,

o tempo, agora,

é de poucas palavras,

e de ainda menos sentido.

Embora eu, pelos vistos,

não tenha razão de queixa.

Senhor, permite que algo permaneça,

alguma palavra ou alguma lembrança,

que alguma coisa possa ter sido

de outra maneira,

não digo a morte, nem a vida,

mas alguma coisa mais insubstancial.

Se não para que me deste os substantivos e os verbos, o medo e a esperança,

a urze e o salgueiro,

os meus heróis e os meus livros?

Agora o meu coração

está cheio de passos

e de vozes falando baixo,

de nomes passados

lembrando-me onde

as minhas palavras não chegam

nem a minha vida

Nem provavelmente o Adalat ou o Nitromint."

Quinta-feira, 5 de março

(PINA, 2012, p. 194) 
A ironia não deixa de comparecer, como que em contrapartida à entonação marcadamente melancólica das três estrofes, ao eclodir ao final do poema com a referência explícita aos nomes de dois remédios, o Adalat e o Nitromint - palavras que não chegam, não resolvem, não atendem, por maior que seja a precisão dos nomes, e dos remédios, que igualmente não curam -, interpondo à camada abstratizante e insubstancial dos versos, sobretudo das duas últimas estrofes, uma outra, a do corpo físico, literal, no sarcasmo absorto de uma leveza quiçá possível em rir de si. Em outro poema, ainda na mesma seção, encontramos a infância e o coração uma vez mais convocados, por meio de uma presentificação verbal tensionada pelo deslocamento da reminiscência:

\section{$\mathrm{X}$}

"A esta hora
na infância neva
e alguém me leva
pela mão.

Quem me trouxe de tão Longe senta-se agora à minha cabeceira pegando-me na mão. Senhor, que ao menos a infância permaneça, o espírito da neve desfolhando-se no chão! $\mathrm{O}$ médico disse que as cicatrizes do coração permanecem."

Sábado, 28 de março

(PINA, 2012, p. 203) 
A convalescença baudelairiana, enquanto renascimento e infância, capacidade de voltar a ver as coisas, talvez possa, nesse sentido, ser entendida em Pina numa modulação perpetrada pela própria contingência do presente - assim como pela consciência de que essa "volta" é sempre, afinal, embora verdadeira a seu modo, apenas metafórica, discursiva -, expressa em seus versos pelo recurso à ironia e a um certo deslizamento entre a linha abstrata do poema, em sua densidade discursiva de viés ontologicamente forte, e a intromissão de elementos externos, literais, por vezes quase cômicos, como que a furar essa linha, da qual a voz enunciativa procura extrair um sentido ainda possível de literário. Como então ler o emprego insistente do coração? Se o "eu”, como vale lembrar, é efeito de discurso, assim como o coração também o seria, parece, no entanto, que há sempre outra coisa, quando, por exemplo, lemos ao final do poema a fala do médico a dizer "As cicatrizes do coração permanecem", no jogo de uma referência literal a um órgão físico, em que as cicatrizes, para além de figurativas ou simbólicas, passam a ser marcas epidérmicas de uma intervenção, de um corte incisivo infligido ao corpo. Como pensar a entonação lírica desses versos? Algo próximo talvez a um lirismo discreto, vigilante, menor, irônico e tardio, que tenta, furtiva e reiteradamente, abrir brechas e espaços de respiro no presente, entre tanto Passado e tanta Literatura? Em seu livro seguinte, Nenhuma palavra, nenhuma lembrança, de 1999, há um poema chamado "Neste preciso tempo, neste preciso lugar" em que lemos:

No princípio era o verbo

(e os açucares

e os aminoácidos).

Depois foi o que se sabe.

Agora debruçado

da varanda de um $3^{\circ}$ andar

e todo o Passado

vem exactamente desaguar 
neste preciso tempo, neste preciso lugar, no meu preciso modo e no meu preciso estado!

Todavia em vez de metafísica

ou de biologia

dá-me para a mais inespecífica

forma de melancolia:

poesia nem por isso lírica

nem por isso provavelmente poesia.

Pois que faria eu com tanto Passado

senão passar-lhe ao lado,

deitando-lhe o enviesado

olhar da ironia?

Por onde vens, Passado, pelo vivido ou pelo sonhado?

Que parte de ti me pertence, a que se lembra ou a que esquece?

Lá em baixo, na rua, passa para sempre gente indefinidamente presente, entrando na minha vida por uma porta de saída que dá já para a memória.

Também eu (isto) não tenho história senão a de uma ausência entre indiferença e indiferença.

(PINA, 2012, p. 252) ${ }^{4}$

Uma resposta parece ser dada nos versos acima, porém, tanto a neutralidade de um "eu" consciente, com a ênfase cautelosa dos parênteses, de ser "isto", quanto o olhar enviesado da ironia, assim como o vazio entre a indiferença e $a$ indiferença, não deixam de denunciar a encenação de uma comoção contraditoriamente desdramatizada, expressa na própria negação da forma de desencanto e nostalgia como "poesia nem

4 A data indicada refere-se ao volume de poesia reunida, intitulado Todas as Palavras - poesia reunida, publicado em 2012. 
por isso lírica/nem por isso provavelmente poesia", o que nos faz pensar aqui num certo sorriso de gato, mencionado por Eduardo Prado Coelho, a respeito da releitura/reescrita, aparentemente sem pathos que Pina faria de Fernando Pessoa, o que também podemos tomar como uma possível forma de enfrentamento desse Passado:

\begin{abstract}
Mas como poderemos definir o que há de específico neste retomar de Pessoa? Eu diria que é um Pessoa aparentemente sem "pathos", num tom deliberadamente menor, um Pessoa oriental, vagamente enigmático, desconcertante como um sorriso de gato, podendo ir ao ponto de ter um sorriso de gato sem gato. Nada do estrepitoso Pessoa ocidental, dividido entre a poesia e a vida, entre a razão e a emoção. É, no seu jeito infantilmente lógico (que nos textos para crianças se torna brincadamente adulto), um Pessoa que entrou no mundo de Alice e que nele gosta de jogar como um gato com o seu novelo de palavras. A relação entre o sujeito e o outro é aqui desdramatizada e estratificada.
\end{abstract}

(COELHO, 2001, n.p.)

\title{
Que emoção?
}

Recobro aqui o pequeno livro de Didi-Huberman sobre a emoção. Nele, o filósofo refere-se, embora muito rapidamente, a Baudelaire, como uma das vozes na poesia que abrirá espaço para a vida sensivel, como afirma, e prossegue aludindo ainda a trabalhos como os de Jean-Paul Sartre, Maurice Merleau-Ponty, Freud e Henri Bergson, voltados para uma reabilitação da noção - já anteriormente empreendida por filósofos do iluminismo e, posteriormente, do romantismo, para alcançar, com a modernidade, um desenvolvimento próprio. Bergson, por exemplo, tomará as emoções como gestos ativos, e não passivos: "gestos que, aliás, reafirmam muito bem o próprio sentido da palavra: uma emoção não seria uma e-moção, quer dizer, uma moção, um movimento que consiste em nos 
pôr para fora (e-, ex) de nós mesmos?" (DIDI-HUBERMAN, 2016, p. 26). Caberia, contudo, atentar aqui para uma diferenciação fundamental entre, por um lado, uma emoção sensorial e corpórea, como no caso do choro de uma criança, conforme a descrição da foto, e, por outro, uma emoção agenciada por uma percepção dirigida, como, por exemplo, no caso de emoções mais intelectivas e filtradas, como as acionadas pela reação a objetos estéticos.

Quanto a isso, a fala de Didi-Huberman diz respeito a emoções que passam por sinais corporais, sinais que todos nós reconhecemos de algum modo, pois são "gestos que fazemos sem nos dar conta de que vêm de muito longe no tempo" (DIDI-HUBERMAN, 2016, p. 32), e que seriam, nesse sentido, como "fósseis em movimento", "moções, movimentos, comoções" (DIDI-HUBERMAN, 2016, p. 38). Nesse aspecto, chama atenção, recobrando a passagem de Nietzsche, uma certa tensão contraditória na convocação de uma segunda, "mais perigosa inocência", de uma infantilidade cem vezes mais refinada, por meio do lugar próprio do corpo do convalescente, seguida, contudo, em seu texto, de uma impiedosa crítica ao homem burguês "culto" e sua fruição da arte, dos livros, da música, enfim, dos prazeres espirituais e do "grito teatral da paixão" do "populacho culto" (NIETZSCHE, 2012, p. 14).

Entretanto, podemos pensar, em contrapartida, em outro tipo de emoção, ligada mais diretamente à ideia de emoção como experiência poética e que nos aproximaria da figura do sujeito lírico. A esse respeito, lemos um sentido da emoção também voltado para uma exterioridade, e não uma interioridade, mas agora segundo as proposições de Michel Collot, em seu livro A matéria-emoção, publicado originalmente em 1997, no contexto mais específico da problemática da experiência estética e poética:

A e-moção não é um estado puramente interior. Como seu nome indica, é um movimento que faz sair de si o sujeito que a experimenta. Ela se exterioriza pelas manifestações 
físicas e se exprime por uma modificação da relação com o mundo. O ser emocionado encontra-se transbordado, tanto por dentro como por fora. Na origem da emoção, sempre há um encontro. $\mathrm{O}$ objeto ou evento que a provoca podem ser internos: um sonho, uma lembrança involuntária, por exemplo. Mas tal objeto ou tal evento apresentamse à consciência de forma inesperada, superando suas expectativas e suas decisões, por isso, menos como uma de suas propriedades que com uma íntima estranheza. (COLLOT, 2018, p. 24)

$\mathrm{Na}$ aposta de que "a emoção, longe de fechar o poeta na esfera da subjetividade, constitui um modo de abertura ao mundo" (2018, p. 23), Collot lança mão de diferentes perspectivas da fenomenologia, da psicanálise e da semiótica, para pensar e tentar circunscrever o que poderia estar em jogo naquilo que ocorre entre a emoção, o sujeito, a feitura do poema e o "movimento de linguagem" (COLLOT, 2018, p. 43) que os perpassa. Assim, no sentido que propõe da emoção como abertura a uma exterioridade, o corpo parece na verdade não estar muito longe: este entre corresponderia a algo da relação entre o "interior" e o "exterior", como, por exemplo, apreendido por Melanie Klein, em seus estudos em torno dos primeiros estágios da vida afetiva; na relação "pré-edípica" com a mãe, segundo a abordagem de Julia Kristeva, por meio do que chama a chora semiótica, nas interações pré-verbais engendradas pelo sujeito; assim como na chamada "área transicional", na acepção de Donald W. Winnicott, como espaço potencial entre o objeto "subjetivo" e o apreendido "objetivamente", ali onde o brincar criativo ${ }^{5}$ pode manifestar-se.

É certo que quando problematizada no contexto de surgimento e consolidação da modernidade poética, a associação entre experiência emocional e experiência poética resvala numa série de impasses, a

5 A "área transicional", segundo Winnicott, corresponderia, por sua vez, ao que o psicanalista nomeia como uma "zona intermediária" ou "terceiro modo de vida" entre a realidade externa e a realidade psíquica interna de cada pessoa: "Em oposição a essas duas realidades, a área disponível para esse terceiro modo de vida (em que existem a experiência cultural e o brincar criativo) é extremamente variável entre os indivíduos. Isso ocorre porque essa área é produto das experiências de cada pessoa (bebê, criança, adolescente, adulto) no ambiente predominante" (WINNICOTT, 2019, p. 171). 
começar pelo controvertido estatuto discursivo do sujeito lírico, a ideia da impessoalidade na poesia, assim como a situação própria de uma "disjunção entre palavra e coisa, entre sujeito e eu, entre linguagem e ela mesma" (MORAES, 2008, p. 196), na esteira de reformulações ocorridas no campo da filosofia, da psicanálise, da linguística e da teoria literária, sobretudo considerando o contexto discursivo do estruturalismo, no decorrer do século XX, passando pela crítica e desfazimento das noções de sujeito e de autor. Como efeito desse quadro amplo, teríamos, no debate contemporâneo sobre a poesia francesa, por exemplo, uma cena movida, a partir da década de 1980, por uma acentuada dualidade entre correntes como a denominada de nouveau lyrisme e outras voltadas para uma tendência "antilírica", como sinaliza Collot (2018, p. 17), que assume, em seu movimento, a clara tentativa de superar essas divisões. ${ }^{6}$

Rosa Maria Martelo aponta uma distinção importante na passagem entre a concepção de poesia do idealismo romântico e a das poéticas da modernidade, relativa a certo discernimento entre diferentes graus de "impessoalidade". A autora refere-se ao dado de que o poema na concepção romântica - voltado para a ideia da poesia como dissolução e integração ao "Todo cósmico" - solicitaria do leitor compreendê-lo sobretudo como "mediação que lhe dá acesso a experiência idêntica" (MARTELO, 2004, p. 217), pois que cada poema em si significaria a manifestação materializada da "memória da poesia", ou seja, nesse sentido, haveria uma não coincidência, de ordem ontológica, entre poesia e poema. Já com as poéticas da modernidade:

os limites da poesia passam, no entanto, a coincidir com os limites do poema ou da escrita poética, desde logo porque

6 'Sabe-se que, há alguns anos, tal debate opõe os defensores de um 'novo lirismo' a uma tendência 'antilírica', que reivindica o 'objetivismo' americano e/ou um 'literalismo' que resulta de Tel Quel' (COLLOT, 2018, p. 17). A esse respeito, podemos mencionar o trabalho de Jean-Michel Maulpoix empreendido em torno da noção de "lirismo crítico". Cf. SISCAR, Marcos. "Ne pas déposer les armes. Continuer néanmoins...". Entretien avec Jean-Michel Maulpoix. Tradução de Marcos Siscar. Revista Criação e Crítica, n. 14, p. 105-114, junho, 2015. Disponível em: http://www.revistas.usp.br/criacaoecritica/article/view/97532. Acesso em: 22 dez. 2019. 
a catábase que Baudelaire encenou na célebre alegoria 'Perte d'auréole' vem lançar o poeta num mundo sem transcendência, ou, talvez seja melhor dizê-lo assim, num mundo reificado onde esta é experimentada como ausência. Por conseguinte, falar da poesia, tornar-se-á um equivalente de falar do poema enquanto entidade discursiva, ou, quando muito, de falar da linguagem poética.

(MARTELO, 2004, p. 218)

É nesse contexto que suas colocações problematizam a elaboração de novos protocolos de leitura surgidos com a criação de novas poéticas e seus possíveis desdobramentos na poesia portuguesa, mais especificamente, na produção a partir de 1975, para tentar entender um "quadro de mudança" que ocorre progressivamente nesse período, "mudança essa que passaria pelo que alguns já chamaram um retorno ao lirismo" (MARTELO, 2004, p. 220), um lirismo figurativo, como frisa, conforme alguns críticos que destaca, como José Luis García Martín e Jean-Michel Maulpoix, o que vai ao encontro do que também já aponta Michel Collot, ao se reportar ao quadro francês. Martelo refere-se ao aparecimento de correntes que advogam, de algum modo, a recuperação do sentido, uma maior aproximação com o leitor e uma certa recusa do teor abstratizante, impessoal e de despersonalização da tradição da modernidade lírica. Um dos exemplos ao qual recorre é Joaquim Manuel Magalhães.

Poderíamos pensar em que medida uma poética como a de Manuel António Pina responderia, ou não, ao desenho apontado por Martelo, sem esquecer que estamos diante de uma poética avessa a qualquer tipo de conformação de época, embora a questão não seja assim evidente. Entre as décadas de 1960 e 1970, em cenas articuladas por poéticas como Poesia 61, a poesia experimental, assim como, mais à frente, pela publicação coletiva de Cartucho, por exemplo, a poesia de Pina aparece como uma voz marcadamente dissonante, desviada de proposições programáticas, no acionamento de modos próprios de diálogo e atrito com a tradição, tanto quanto com produções de seu tempo, mesmo se por intermédio de 
certa indiferença assumida, o que terá como reflexo inclusive alguma incompreensão por parte da crítica quando do seu aparecimento, como bem indicado no poema "[Aos meus livros]":

Chamaram-vos tudo, interessantes, pequenos, grandes, ou apenas se calaram, ou fecharam os longos ouvidos à vossa inútil voz passada em sujos espelhos buscando o rosto e as lágrimas que (eu é que sei!) me pertenciam, pois era eu quem chorava.

Um bancário calculava que tínheis curto saldo de metáforas; e feitas as contas (porque os tempos iam para contas) a questão era outra e ainda menos numerosa (e seguramente, aliás, em prosa).

Agora, passando ainda para sempre, olhais-me impacientemente; como poderíamos, vós e eu, escapar sem de novo o trair, a esse olhar? Levai-me então pela mão, como nos levam os filhos pela mão: sem que se apercebam.

Partiram todos, os salões onde ecoavam ainda há pouco os risos dos convidados estão vazios; como vós agora, meus livros: papéis pelo chão, restos, confusos sentidos. (E só nós sabemos que morremos sozinhos. Ao menos escaparemos à piedade dos vizinhos)

(PINA, 2018, p. 65)

Se, da frase de Nietzsche, tomada pelo contexto de seu surgimento 
e da atmosfera que a provocou, é possível apreender a relação entre a ideia de convalescença e a de uma "segunda inocência", o que, por sua vez, nos leva à associação baudelairiana da figura do convalescente e a da criança, referência direta a um entendimento dessa infância como índice emblemático da modernidade poética, a "segunda inocência" de Pina parece, contudo, ir mais adiante. A convalescença baudelairiana, como recuperação da capacidade de voltar a ver as coisas, não escapa a uma modulação que em Pina se daria pela consciência mesma de que esse retorno é, afinal, efeito de linguagem, desilusão e desencanto expressos de tantos modos em seus versos por meio da ironia de um escritor que irrevogavelmente se sabe "retórico com cega serenidade", na citação, nas desmontagens sintáticas, assim como em certos deslizamentos de elementos de fora para dentro da esfera discursiva dos poemas, com a voz enunciativa em intermitente desajuste, dividida entre a voz literal e a voz de Literatura. Modulação que se traduziria ainda na densidade discursiva de viés ontologicamente forte, muitas vezes interrompida de forma abrupta por elementos externos, e que poderia ser sintetizada pela afirmação de Rui Lage quando se refere a um encontro "no mesmo poema, da densidade metafísica com o quotidiano doméstico" (LAGE, 2016, p. 45) como uma das características maiores dessa poética. E é provável que seja na sustentação própria desse encontro, que possamos ler a figuração furtivamente irônica de um coração no entre desses dois lados, coração que no verso pode ser o livro mesmo como pergunta, este algo, este isto dizendo afinal "eu" em meio a uma "inumerável voz": "É isto um livro,/esta espécie de coração (o nosso coração)/dizendo ‘eu’ entre nós e nós?” (PINA, 2012, p. 357).

\section{Referências}

BAUDELAIRE, Charles. Poesia e prosa. Organização Ivo Barroso. Rio de Janeiro: Nova Aguilar, 1995. 
COELHO, Eduardo Prado. Sobe as escadas, bate à porta. Público/Caderno Ípsilon, 10 nov. 2001. Disponível em: https://www.publico.pt/2001/11/10/ jornal/sobe-as-escadas-bate-a-porta-164035. Acesso em: 12 nov. 2019.

COLLOT, Michel. A matéria-emoção. Tradução Patricia Souza Silva. Rio de Janeiro: Oficina Raquel, 2018.

DIDI-HUBERMAN, Georges. Que emoção! Que emoção? Tradução Cecília Ciscato. São Paulo: Editora 34, 2016.

HOUAISS, Antônio. Novo dicionário Houaiss da Língua Portuguesa. São Paulo: Ed. Objetiva, 2009.

KRISTEVA, Julia. La révolution du langage poétique - L'avant-garde à la fin du XIX ${ }^{\mathrm{e}}$ siècle : Lautréamont et Mallarmé. Paris : Éditions du Seuil, 1974 (1985).

LAGE, Rui. Manuel António Pina. Coimbra: Impressa da Universidade de Coimbra, 2016.

MARTELO, Rosa Maria. Em parte incerta: Estudos de poesia portuguesa moderna e contemporânea. Porto: Campo das Letras, 2004.

MORAES, Marcelo Jacques de. O lugar das coisas: Francis Ponge e Christophe Tarkos. In:ALVES, Ida; PEDROSA, Celia (org.). Subjetividades em devir. Rio de Janeiro: 7Letras, 2008.

NIETZSCHE, Friedrich. A gaia ciência. Tradução Paulo César de Souza. São Paulo: Companhia das Letras, 2012.

PINA, Manuel António. Cuidados Intensivos. Porto: Afrontamento, 1994. . Dito em voz alta: Entrevistas sobre literatura, isto é, sobre tudo. Lisboa: Documenta, 2016.

. O coração pronto para o roubo: antologia. Organização Leonard Gandolfi. São Paulo: Editora 34, 2018. 
- Nenhuma palavra e nenhuma lembrança. Lisboa: Assírio \& Alvim, 1999.

. Todas as Palavras: poesia reunida. Lisboa: Assírio \& Alvim, 2012.

QUEIRÓS, Luís Miguel. A auto-ironia é afastar-me de mim, deixar desamparado. Público, [S.1.], 17 jun. 2011. Caderno Ípsilon. Disponível em: <https://www.publico.pt/2011/06/17/jornal/a-autoironia-e-afastarmede-mim-deixarme-desamparado-22277928>. Acesso em: 06 dez. 2019. [Entrevista a Manuel António Pina]

SISCAR, Marcos. Entrevista com Jean-Michel Maulpoix. Tradução Marcos Siscar. Revista Criação e Crítica, [S.1.], n. 14, p. 105-114, junho, 2015. Disponível em: http://www.revistas.usp.br/criacaoecritica/article/ view/97532. Acesso em: 22 dez. 2019.

SOUZA, Paulo Cézar de. Prólogo. In: NIETZSCHE, Friedrich. A gaia ciência. Tradução Paulo César de Souza. São Paulo: Companhia das Letras, 2012.

WINNICOTT, Donald. O brincar e a realidade. Tradução Breno Longhi. São Paulo: Ed. Ubu, 2019.

Recebido em: 18/06/2020

Aprovado em: 13/07/2020 